\title{
RACIONALIDADE TÉCNICA E A FORMAÇÃO DE PROFESSORES DE LÍNGUAS ESTRANGEIRAS EM UM CURSO DE LETRAS
}

\author{
Telma Nunes GIMENEZ ${ }^{1}$ \\ Viviane Bagio FURTOSO
}

\section{Resumo}

Neste texto discutimos aspectos da formação profissional na área de Letras, com destaque para a área de línguas estrangeiras modernas, a partir do processo de reformulação curricular em uma universidade do Norte do Paraná. As discussões que culminaram com a opção pelo fim das licenciaturas duplas foram marcadas pelos entendimentos sobre a relação teoria/prática, analisadas sob a luz da abordagem reflexiva de formação profissional. Inicialmente influenciada pela visão da 'racionalidade técnica' a nova proposta foi modificada a fim de contemplar a educação de professores de línguas estrangeiras em uma perspectiva de um redimensionamento entre aportes teóricos e atividades práticas. Foram também considerados os parâmetros das diretrizes curriculares para os cursos de formação de professores.

Palavras-chave: currículo, língua estrangeira, abordagem reflexiva.

\section{Introdução}

O curso de Letras da Universidade Estadual de Londrina (UEL) completou 50 anos em 2006 (SILVA, 2006). Como um dos cursos mais antigos da Universidade, goza de prestígio e tradição. Ao longo de sua história seu currículo passou por várias transformações. A mais recente que desmembrou a licenciatura dupla em única é objeto de reflexão neste texto.

Todo processo de discussão curricular traz, em seu bojo, conflitos e esperanças. Conflitos porque o novo pode desestabilizar o conhecido, o familiar, o seguro. Esperanças porque a partir dessa desestabilização podem ser construídos novos paradigmas, maneiras antes não pensadas de se conduzir a formação de nossos alunos.

\footnotetext{
${ }^{1}$ Professora Associada do Departamento de Letras Estrangeiras Modernas da UEL. Docente do Programa de Pós-graduação em Estudos da Linguagem. Pesquisadora CNPq.

${ }^{2}$ Professora Assistente do Departamento de Letras Estrangeiras Modernas da UEL. Coordenadora do Curso de Letras Estrangeiras Modernas e doutoranda na UNESP.
} 
São nesses momentos do microcosmo dos arranjos curriculares que pressupostos tidos como verdadeiros pelos tomadores de decisão vão sendo verbalizados e o projeto do currículo vai tomando forma.

Este texto tem por objetivo registrar o momento em que o currículo do curso de Letras da Universidade Estadual de Londrina (UEL), caracterizado como texto, foi aprovado. Compartilhamos da visão de Silva (2001) quando afirma que o currículo constrói identidades e se atrela a visões de mundo, sujeitas a questionamentos. Segundo o autor:

O currículo desloca certos procedimentos e concepções epistemológicas, colocando outros em seu lugar. A política curricular, metamorfoseada em currículo, efetua, enfim, um processo de inclusão de certos saberes e de certos indivíduos, excluindo outros (SILVA, 2001, p. 11).

Para ele, no currículo são travadas lutas pelo controle hegemônico e domínio dos processos de significação. Pensar o currículo como terreno de luta em torno da representação significa concebê-lo também como manifestação de poder.

No caso em questão, a significação pela qual se travou a discussão à época era de que o conhecimento poderia ser estático, descontextualizado, algo a ser transmitido, em uma visão tecnicista de formação profissional.

Dois aspectos centrais do novo currículo puseram em relevo esta questão. Um deles foi o entendimento de que a formação para o bacharelado e para o magistério se daria de modo semelhante em virtude do conhecimento "fundamental" a ser compartilhado. Nesta perspectiva, tradicional de acordo com Silva (2001), o currículo “é pensado como um conjunto de fatos, de conhecimentos e de informações, selecionados do estoque cultural mais amplo da sociedade, para serem transmitidos” (p. 13). Furtoso (2003, p. 127) afirma que:

De certo modo, essa interpretação é uma abertura das próprias diretrizes curriculares para os cursos de Letras, onde podemos encontrar orientações generalistas que servem, para muitos de nós, como um "amuleto para se defender" das propostas das Diretrizes Curriculares Nacionais para a Formação de Professores da Educação Básica (Resoluções do Conselho Nacional de Educação CNE/CP1 e $\mathrm{CNE} / \mathrm{CP} 2)$. 
O segundo ponto diz respeito à concepção de que formar professores em língua estrangeira é só uma questão de agregar umas poucas disciplinas ao currículo da licenciatura única em língua portuguesa. Conforme já destacado por Furtoso (2003), “demarcar território tem se constituído numa forma de tentar garantir os parâmetros pedagógicos calcados na certeza do saber objetivo e previsível presente hoje nas diferentes áreas de conhecimento dentro de um próprio curso de graduação” (p. 131).

Depois de muitos anos de discussão e tentativas de propor um novo projeto pedagógico que mantivesse a existência de licenciaturas duplas na UEL, chegou-se à conclusão de que nem uma das duas especificidades (bases de conhecimento em língua materna e em uma língua estrangeira) seria adequadamente contemplada em uma proposta desta natureza. Assim, optou-se, em 2005, pela divisão em dois cursos ao invés de um, como tradicionalmente vinha sendo feito.

Atualmente a área de Letras na UEL está dividida em dois cursos: Letras e Letras Estrangeiras Modernas. O curso de Letras compõe-se de duas modalidades: licenciatura e bacharelado. A licenciatura é em Língua Portuguesa e respectivas literaturas. O Bacharelado compõe-se de duas habilitações: Estudos da Linguagem e Estudos Literários. O curso de Letras Estrangeiras Modernas é ofertado apenas na modalidade de licenciatura, em duas habilitações possíveis: Língua Inglesa e respectivas literaturas e Língua Espanhola e respectivas literaturas. Na área de línguas estrangeiras modernas, no ano de 2008, há dois currículos em curso. O currículo em extinção está em seu último ano e o novo em seu terceiro ano.

Para que possamos entender o caminho percorrido para se chegar ao formato em que o curso de Letras da UEL se encontra hoje, conforme descrito anteriormente, este artigo está dividido em quatro seções. Na primeira, a seguir, apresentaremos a proposta inicial de um novo currículo para o curso de Letras da UEL e seu encaminhamento no que diz respeito às línguas estrangeiras. As seções 2 e 3 serão dedicadas à discussão de dois dos principais problemas que a aprovação do currículo, conforme apresentado na seção 1, desencadearia na formação acadêmica dos discentes do curso em questão. E, antes das considerações finais, será descrito o novo currículo do Curso Letras Estrangeiras Modernas - Habilitação: Licenciaturas em Língua Inglesa e Respectivas Literaturas, e, em Língua Espanhola e Respectivas Literaturas. 


\section{Proposta inicial para reformulação do currículo de letras da uel}

O antigo currículo permitia quatro escolhas ao aluno: Licenciatura única em Língua Portuguesa e Licenciaturas Duplas em Português/Inglês, Português/Francês e Português/Espanhol com respectivas literaturas. No processo de discussão do novo currículo foi apresentada uma proposta (primeira versão do currículo) na qual foram acrescentados os bacharelados em estudos lingüísticos e literários e acrescido um ano para as licenciaturas duplas. No entanto, os cursos teriam uma matriz comum.

O quadro 1 abaixo mostra a distribuição de carga horária e atividades apenas para as licenciaturas duplas que foram propostas pelo projeto de novo currículo:

\begin{tabular}{|l|l|l|l|l|l|l|}
\hline Licenciatura Dupla & 1 Ano & 2 Ano & 3 Ano & 4 Ano & 5 Ano & Total \\
\hline Módulos Básicos & 544 & & & & & 544 \\
\hline Prática de Ensino I & & & & 68 & 68 & 136 \\
\hline Prática de Ensino II & & & & 68 & 68 & 136 \\
\hline Módulo Linguagem e educação & & 136 & & & & 136 \\
\hline Disciplinas em língua portuguesa & & 408 & 476 & 204 & 136 & 1224 \\
\hline Disciplinas em língua estrangeira & 136 & 136 & 204 & 204 & 136 & 816 \\
\hline Formação livre & & & & 136 & 272 & 408 \\
\hline Formação complementar & 200 & & & & & 200 \\
\hline Estágio supervisionado & 400 & & & & & 400 \\
\hline Total & 680 & 680 & 680 & 680 & 680 & 4000 \\
\hline
\end{tabular}

Quadro 1: Proposta de licenciatura dupla na primeira versão do novo currículo

A inovação trazida pela proposta era a de ensino em módulos. A formação comum, necessária, é verdade, a todo profissional de Letras, poderia ter se restringido a módulos básicos do $1^{\circ}$. ano ${ }^{3}$ (em número de 4 e perfazendo 544 horas), e no espírito da LDB, ter acoplada a flexibilidade necessária ao aluno. No entanto, não foi o que aconteceu. Tendo o núcleo comum em módulos sido considerado inadequado para ministrar disciplinas essenciais, a opção foi pela clássica oferta de disciplinas,

\footnotetext{
${ }^{3}$ Os módulos eram: O profissional de Letras, Percursos da leitura e da escrita. Linguagem como manifestação artística e literária e Linguagem e identidades.
} 
caracterizando territórios conquistados e por conquistar, sob a alegação de que nenhum profissional de Letras pode ignorar aspectos de sintaxe, teoria da literatura, semântica ou fonética e fonologia. Ou seja, a reiteração do currículo mínimo, definido a partir da visão “conteudística” de formação na língua portuguesa.

Um rol de disciplinas de lingüística e literatura ocupou espaços antes destinados à formação filosófica, sociológica ou educacional. A prática foi entendida como atribuição das aulas de língua estrangeira, práticas de ensino e estágios supervisionados. É bem verdade que os módulos previam carga horária prática, mas este princípio não prevaleceu para as demais disciplinas “de base”. Todas, sem exceção, eram teóricas e muitas seriam partilhadas com o bacharelado.

Pesquisadores na área de formação de professores de línguas se espantarão, com certeza, com esta postura. Afinal, os debates atuais, refletidos nas diretrizes das licenciaturas, procuram identificar alternativas para a formação que não tem dado certo: a formação técnica, independente do ofício que se vai exercer.

Apesar do acréscimo de horas nas licenciaturas duplas (de 2.858 para 4.000), dos módulos temáticos no primeiro ano e da possibilidade de flexibilização oferecida pela legislação, prevaleceu, na proposta, a manutenção de disciplinas. Assim, as 200 horas de atividades complementares previstas nas diretrizes das licenciaturas teriam que ser cumpridas fora da grade curricular. No entanto, Paiva (2003, p.80) nos alerta:

O currículo, nas novas diretrizes, não é mais entendido como a soma de disciplinas distribuídas em uma grade curricular. Apesar de não descartar as disciplinas convencionais, o novo texto legal introduz o conceito de atividade curricular, abrindo a possibilidade para que o graduando possa completar seus créditos com atividades, tais como iniciação científica, atividades de extensão, participação em eventos, etc. A articulação entre ensino, pesquisa e extensão é condição necessária para a implementação de um currículo flexível.

Os alunos dos cursos noturnos, especialmente, que antes tinham espaços na grade curricular para desenvolver as atividades complementares, teriam que realizá-las em outro tempo.

Pautadas inicialmente apenas pelas diretrizes curriculares para os cursos de Letras, que têm um forte viés para o bacharelado (ao considerar como base da formação apenas as áreas de estudos lingüísticos e literários, excluindo, por exemplo, a formação 
pedagógica), as discussões não foram aprofundadas no que dizia respeito às diretrizes para as licenciaturas. Como resultado, tínhamos um currículo que não privilegiava a prática e se caracterizava pela racionalidade técnica (SCHÖN, 1983).

Não bastasse o alinhamento com um modelo hoje questionado em praticamente todas as esferas acadêmicas, víamos a formação de professores relegada a um segundo plano. Neste texto abordaremos dois dos principais problemas que seriam trazidos caso o currículo fosse aprovado como estava: o pressuposto de que alunos de licenciaturas e bacharelado podem partilhar da formação comum e a noção de que a formação em língua estrangeira na habilitação dupla é supérflua e acessória.

\section{Racionalidade técnica e formação de professores}

Há muito se advoga que o quadro educacional brasileiro só terá avanços à medida que formarmos professores bem preparados. Obviamente, outros fatores são igualmente importantes para se alcançar melhorias nas escolas, mas não se pode negar o valor de profissionais comprometidos com educação de qualidade para todos. Entendemos que cabe às instituições de ensino superior imprimir rumos a essa formação, por meio de currículos que reflitam concepções atualizadas e coerentes com as demandas sociais. No entanto, as diferentes concepções do que é conhecimento válido e necessário tornam essas definições um campo de lutas, conforme salientado por Silva (2001) e Apple (2002), dentre outros. Assim, gostaríamos de apresentar uma concepção de formação alternativa ao modelo tradicional e tecnicista traduzido em defesas de manutenção de disciplinas consideradas básicas, teóricas, que trariam conhecimentos a serem aplicados posteriormente.

Desde a década de 1980 temos assistido a críticas constantes ao modelo da racionalidade técnica, caracterizado por Schön (1983) como aquele que deriva sua autoridade das ciências. Formar professores, nesse contexto, seria ensinar os conhecimentos trazidos pelas pesquisas científicas. A prática adquiriria um caráter meramente instrumental. O fracasso desse modelo, que tem dominado inclusive os cursos de Letras, levou à proposta de uma formação reflexiva, em que conhecimentos teóricos e práticos são articulados. De acordo com Pimenta (2002, p. 22): 
O ensino como prática reflexiva tem se estabelecido como uma tendência significativa nas pesquisas em educação, apontando para a valorização dos processos de produção do saber docente a partir da prática e situando a pesquisa como um instrumento de formação de professores, em que o ensino é tomado como ponto de partida e de chegada da pesquisa.

Na esteira desse movimento, diversos tipos de conhecimento ou saberes que compõem o trabalho do professor foram postulados (SHULMAN, 1987; TARDIF, 2002). De acordo com esses autores, não se pode aceitar que para ensinar basta conhecer o conteúdo disciplinar. Um currículo voltado para a formação de professores não pode ignorar que diversos saberes irão compor essa formação e esses advirão não somente dos preceitos teóricos mas também da prática, que náo pode ficar restrita a um curto período de estágio supervisionado.

Os cursos de Letras, por seu histórico, têm um forte viés de formação bacharelesca, embora a maioria dos egressos acabe atuando no magistério (GIMENEZ, 2003). Para Paiva, apesar de a grande maioria dos cursos serem de licenciatura, a vocação do corpo docente da área de Letras, por exemplo, continua muito voltada para um perfil de bacharelado, pois poucos são os docentes interessados em questões de ensino/aprendizagem. Este viés também pode ser verificado nos objetivos traçados a partir das diretrizes estabelecidas pelo MEC/SESu para a área de Letras e alguns deles adotados pelo curso da UEL, tais como formar: 1. profissionais de Letras, independente de sua habilitação em bacharelado ou licenciatura - daí o curso se caracterizar por um núcleo comum, composto de módulos temáticos; 2. leitores críticos e agentes eficazes da cidadania, que sejam capazes de fazer uso da linguagem nas suas diferentes manifestações; 3. profissionais interculturalmente competentes, capazes de lidar, de forma crítica, com as linguagens, especialmente a verbal, nos contextos oral e escrito, e conscientes de sua inserção na sociedade e das relações com o outro; 4. profissionais que tenham domínio do uso da língua ou das línguas que sejam objeto de seus estudos, em termos de sua estrutura, funcionamento e manifestações culturais, além de ter consciência das variedades lingüísticas e culturais; 5. profissionais com capacidade de reflexão crítica sobre temas e questões relativas aos conhecimentos lingüísticos e literários; 6. pessoas capazes de visualizar meios de articulação dos saberes com a pesquisa, o ensino e a extensão, dentre outros. 
O desejo de atrelar ambos os tipos de formação (bacharelado e licenciatura) sob o mesmo teto da lingüística e literatura não deixa espaço para aquilo que as diretrizes das licenciaturas ${ }^{4}$ tanto enfatizam, ou seja, a prática permeando o curso desde seu início. Prática, neste caso, não deve ser confundida com prática de ensino. A Resolução CNE/CP 1, de 18 de fevereiro de 2002, em seu Art. 12, salienta:

$\S 1^{\circ}$ A prática, na matriz curricular, não poderá ficar reduzida a um espaço isolado, que a restrinja ao estágio, desarticulado do restante do curso.

$\S 2^{\circ}$ A prática deverá estar presente desde o início do curso e permear toda a formação do professor.

$\S 3^{\circ}$ No interior das áreas ou das disciplinas que constituírem os componentes curriculares de formação, e não apenas nas disciplinas pedagógicas, todas terão a sua dimensão prática.

É interessante também observar o descompasso entre os objetivos do curso e as atividades propostas. Apesar da referência à “reflexão crítica e de pesquisa” em ambas as modalidades, um módulo de pesquisa, na primeira versão do currículo do curso de Letras da UEL, foi incluído apenas para a opção do bacharelado, ficando linguagem e educação para as licenciaturas. Isto contrariava as próprias diretrizes das licenciaturas que prevêem no Inciso III do Art. $3^{\circ}$ que, no preparo profissional específico, deve ser incluída "a pesquisa, com foco no processo de ensino e de aprendizagem, uma vez que ensinar requer, tanto dispor de conhecimentos como mobilizá-los para a ação, como compreender o processo de construção do conhecimento”. Igualmente, no inciso V do Art. $6^{\circ}$, são listadas entre as competências a serem consideradas na construção do projeto pedagógico, “aquelas referentes ao conhecimento de processos de investigação que possibilitem o aperfeiçoamento da prática pedagógica”.

Uma possível explicação para este arranjo é que a pesquisa no bacharelado não teria como foco questões de ensino/aprendizagem. Se a pesquisa não teria um módulo específico na licenciatura, pressupõe-se, portanto, que os professores adotariam uma perspectiva de investigação em suas disciplinas para os alunos de licenciatura, o que,

\footnotetext{
${ }^{4}$ Embora circulem boatos de que as diretrizes serão revogadas, não se sabe ao certo se isto se refere a todas as diretrizes dos cursos de graduação ou apenas as das licenciaturas. Se forem todas, as discussões deverão ser pautar por outros critérios, ainda não esclarecidos.
} 
por si só, já requereria que bacharéis e licenciandos freqüentassem turmas diferenciadas. No entanto, não era o que estava previsto.

A necessidade de articulação entre conteúdos e didáticas - e não um antecedendo o outro - demandava se pensar que bacharelados e licenciaturas precisariam de currículos distintos, embora com pontos em comum. A separação entre bacharelado e licenciatura está recomendada pelo próprio Conselho Nacional de Educação que, no Parecer CNE/CP 009/2001, p. 6, afirma:

[...] a Licenciatura ganhou, como determina a nova legislação, terminalidade e integralidade própria em relação ao bacharelado, constituindo-se em um projeto específico. Isso exige a definição de currículos próprios da licenciatura que não se confundem com o Bacharelado ou com a antiga formação de professores que ficou caracterizada como modelo " $3+1$ " .

A persistência no modelo " $3+1$ ” só pode ser explicada pelo apego à tradição e a dificuldade de se desvincular do currículo mínimo do curso de Letras, antes obrigatório. Seria fundamental criar espaços para que todos os docentes do curso discutissem os diferentes modelos de formação profissional, seus pressupostos e suas conseqüências. Conforme já apontado em Furtoso (2003), reconhecer a necessidade de projetos pedagógicos diferenciados não implica priorizar a prática colocando o conteúdo em segundo plano, como muitos professores têm mencionado, mas priorizar um tratamento diferenciado deste conteúdo, fundamental na formação do professor da educação básica.

\section{Formação do professor de língua estrangeira}

Um dos grandes desafios para o sistema educacional é incorporar, em práticas, o reconhecimento da importância da língua estrangeira na formação integral dos educandos. Apesar do ensino de línguas estrangeiras ser uma tradição no Brasil (CELANI, 1994; LEFFA,1999), seu ensino em escolas das redes pública e privada tem sofrido o impacto de cargas horárias insuficientes, excesso de número de alunos em sala e falta de materiais didáticos apropriados. Soma-se a isto um professor com preparo aquém do necessário e temos um quadro de fracasso já tratado em vários trabalhos.

\footnotetext{
${ }^{5}$ Neste modelo, os alunos cursam primeiro as disciplinas de conteúdo e depois as pedagógicas, modelo, aliás, típico da racionalidade técnica.
} 
Parte do problema deriva do modo como a formação do professor de língua estrangeira é realizada, como apêndice das licenciaturas únicas em língua portuguesa, conforme o currículo antigo do curso de Letras da UEL deixava transparecer. Embora o currículo não seja entendido apenas como disciplinas e sua carga horária, é nestes aspectos que aparece de modo mais claro o entendimento de que a língua estrangeira se restringe a aulas para desenvolvimento de proficiência lingüística. Um comparativo das disciplinas ofertadas na licenciatura única em língua portuguesa e na habilitação dupla Português/língua estrangeira revelava que TODAS as disciplinas da licenciatura única seriam obrigatórias para os alunos da dupla. Assim, de um total de 4.000 horas do curso, a língua estrangeira, suas literaturas e as práticas de ensino ficam com pouco mais de 1.000 horas. Seria possível ampliar essa formação se o aluno escolhesse disciplinas da formação livre $(136 h+272 h)$ e as atividades complementares $(200$ h) somente desta área.

A valorização excessiva da língua portuguesa na formação do professor de língua estrangeira é um fato também comentado por Paiva (2005, p.360) que alerta:

Os projetos pedagógicos em vigor nas licenciaturas duplas continuam
privilegiando os conteúdos em língua portuguesa, ficando a língua
estrangeira com pouquíssimo espaço na grade curricular. As
literaturas, espaço essencial para que o aprendiz tenha input autêntico,
experiência estética e imersão na outra cultura, ficam relegadas,
geralmente, a duas disciplinas de 30 ou 60 horas. Conteúdos de
formação do professor de língua estrangeira são, geralmente,
ignorados, e é raro o curso que oferece atividades curriculares que
estimulem reflexões sobre a aquisição, ensino e aprendizagem de
língua estrangeira.

Tal como se apresentava, a proposta revelava o desprezo pela formação em língua estrangeira quando se procurava unir as duas formações. Reiteramos que não se nega que haja conhecimentos comuns a ambas as habilitações, mas daí a considerar que a mesma formação da licenciatura única em língua portuguesa deva acontecer na licenciatura dupla demonstra o que Silva (2001) bem caracteriza: o currículo como espaço de poder. Parece óbvio que na junção de duas licenciaturas não é possível ocupar os mesmos espaços que uma licenciatura única proporcionaria, a não ser que o curso se estendesse por muitos anos ou que uma das formações ficasse prejudicada; neste caso, a formação em língua estrangeira. Lamentavelmente, a perspectiva de que a língua estrangeira é apêndice não é privilégio apenas do ensino fundamental e médio. Também 
em nível de preparação dos professores esta atitude pode ser extremamente prejudicial e ter sérias conseqüências para os profissionais que atuarão naqueles níveis da educação básica.

Por isso mesmo, Paiva (2003) comenta sobre esse círculo vicioso, e discute a possibilidade de desmembramento das licenciaturas, ou seja, o fim das licenciaturas duplas. Uma outra solução, segundo ela,

[...] seria uma regulamentação dos cursos de licenciatura dupla em que se definisse com muita clareza os dois projetos - formação de professor de língua portuguesa e formação de professor de língua inglesa - e o núcleo comum aos dois projetos. É necessário que seja fixado um percentual de horas mínimas a serem dedicadas ao ensino de línguas estrangeiras, que, no meu entender, não deveria ser inferior a 1400 horas. Não se pode ignorar que o aluno já adquiriu o português ao se decidir pelo curso de Letras e que, com raras exceções, o mesmo acontecerá com a língua estrangeira. (p. 78)

Assim, tanto a visão de que teoria precede e dá direção à prática quanto a de que a língua estrangeira não merece lugar de destaque em uma licenciatura dupla levaram à busca de alternativas que pudessem, efetivamente, permitir a formação de bons profissionais, tanto em língua portuguesa quanto em língua estrangeira (GIMENEZ, CRISTOVÃO, 2005). O que não parecia aconselhável era sacrificar um tipo de educação em função da outra. A solução encontrada foi manter os cursos separados. De acordo com o documento final contendo as diretrizes do projeto político-pedagógico do novo curso,

Parafraseando Cecília Meireles, “ou me formo em Vernáculas”, “ou me aprofundo em Línguas Estrangeiras" e isso alertava para o fato de que a habilitação dupla mantinha uma incoerência: ou se forma um aluno proficiente e apto a atuar no ensino de língua estrangeira, ou se forma um aluno capaz de pensar criticamente a língua portuguesa e suas expressões literárias. A solução foi direcionar o curso para a formação em Licenciatura Única” (p. 4).

\section{O novo currículo e a licenciatura única}

Tomada a decisão, foi então criado o curso de Letras Estrangeiras Modernas, na modalidade licenciatura, com duas habilitações, uma em inglês e outra em espanhol. 
Francês se constituiu como uma habilitação opcional em língua e cultura francesa ${ }^{6}$. O curso tem a duração de quatro anos, divididos em 4 séries. As habilitações em inglês e espanhol compartilham de um tronco comum na primeira série, conforme quadro 2. Até 2007 a escolha pela língua estrangeira se dava ao final desse primeiro ano, porém a partir de 2008 a escolha passou a ser feita no vestibular.

\begin{tabular}{l|l|l|l|}
\hline \multirow{2}{*}{ Nome } & \multicolumn{3}{|l|}{ Carga Horária } \\
\cline { 2 - 5 } & Teór. & Prát. & Tot. \\
\hline Língua Inglesa I A & - & 136 & 136 \\
\hline Língua Espanhola I A & - & 136 & 136 \\
\hline Leitura em Língua Inglesa & - & 68 & 68 \\
\hline Unidade e Diversidade da Língua Espanhola & 68 & - & 68 \\
\hline Lingǘstica I & 68 & - & 68 \\
\hline Lingǘstica II & 68 & - & 68 \\
\hline Produção de Texto I & - & 68 & 68 \\
\hline Língua e Sociedade & 68 & - & 68 \\
\hline Total & $\mathbf{2 7 2}$ & $\mathbf{4 0 8}$ & $\mathbf{6 8 0}$ \\
\hline
\end{tabular}

Quadro 2: Tronco comum do curso de Letras Estrangeiras Modernas.

O quadro 3 sintetiza as disciplinas e carga horária para as duas habilitações. É importante destacar que a maioria das disciplinas está a cargo do Departamento de Letras Estrangeiras Modernas, inclusive aquelas mais diretamente relacionadas a questões educacionais.

\begin{tabular}{|c|c|c|c|c|}
\hline \multirow[t]{2}{*}{ Série } & \multicolumn{2}{|l|}{ Inglês } & \multicolumn{2}{|l|}{ Espanhol } \\
\hline & Disciplina & $\begin{array}{l}\text { Carga } \\
\text { horária }\end{array}$ & Disciplina & $\begin{array}{l}\text { Carga } \\
\text { horária }\end{array}$ \\
\hline $2^{\mathrm{a}}$ & $\begin{array}{l}\text { Língua Inglesa } \\
\text { Morfossintaxe da LI } \\
\text { Lingüística Aplicada } \\
\text { Teoria de textos literários }\end{array}$ & $\begin{array}{l}204 \\
68 \\
136 \\
136\end{array}$ & $\begin{array}{l}\text { Língua Espanhola } \\
\text { Gramática da língua espanhola } \\
\text { Lingüística Aplicada } \\
\text { Teoria de textos literários }\end{array}$ & $\begin{array}{l}204 \\
68 \\
136\end{array}$ \\
\hline
\end{tabular}

\footnotetext{
${ }^{6}$ Para detalhes consultar http://www.uel.br/col/letrasestrangeirasmodernas/.
} 


\begin{tabular}{|c|c|c|c|c|}
\hline & $\begin{array}{l}\text { Filosofia e Linguagem } \\
\text { Formação livre } \\
\text { Total }\end{array}$ & $\begin{array}{l}68 \\
68 \\
680\end{array}$ & $\begin{array}{l}\text { Filosofia e Linguagem } \\
\text { Formação livre } \\
\text { Total }\end{array}$ & $\begin{array}{l}136 \\
68 \\
68 \\
680\end{array}$ \\
\hline $3^{\mathrm{a}}$ & $\begin{array}{l}\text { Língua Inglesa } \\
\text { Literaturas de Língua Inglesa } \\
\text { Fonologia da LI } \\
\text { Ensino de LI na educação } \\
\text { básica } \\
\text { Educação para inclusão } \\
\text { Estágio } \\
\text { Optativa } \\
\text { Formação livre } \\
\text { Total }\end{array}$ & $\begin{array}{l}204 \\
136 \\
68 \\
68 \\
68 \\
200 \\
68 \\
68 \\
880\end{array}$ & $\begin{array}{l}\text { Língua Espanhola } \\
\text { Literaturas de Língua } \\
\text { Espanhola } \\
\text { Gramática de Língua } \\
\text { Espanhola } \\
\text { Metodologia do Ensino de } \\
\text { Língua Espanhola } \\
\text { Educação para inclusão } \\
\text { Estágio } \\
\text { Optativa } \\
\text { Formação livre }\end{array}$ & $\begin{array}{l}204 \\
136 \\
68 \\
68 \\
68 \\
160 \\
68 \\
68 \\
840\end{array}$ \\
\hline $4^{\mathrm{a}}$ & $\begin{array}{l}\text { Língua Inglesa } \\
\text { Literaturas de Língua Inglesa } \\
\text { Ensino de LI na educação } \\
\text { básica } \\
\text { Língua inglesa para sala de } \\
\text { aula } \\
\text { Estágio } \\
\text { Optativas } \\
\text { Formação livre } \\
\text { Total }\end{array}$ & $\begin{array}{l}204 \\
136 \\
68 \\
68 \\
200 \\
136 \\
68 \\
880\end{array}$ & $\begin{array}{l}\text { Língua Espanhola } \\
\text { Literaturas de Língua } \\
\text { Espanhola } \\
\text { Metodologia do Ensino de } \\
\text { Língua Espanhola } \\
\text { Prática de Ensino } \\
\text { Estágio } \\
\text { Optativas } \\
\text { Formação livre } \\
\text { Total }\end{array}$ & \begin{tabular}{|l|}
204 \\
136 \\
68 \\
68 \\
240 \\
136 \\
68 \\
920
\end{tabular} \\
\hline
\end{tabular}

Quadro 3: Grade curricular do curso de Letras Estrangeiras Modernas? .

Como se pode observar, no novo currículo ainda são mantidas disciplinas em língua portuguesa e há maior flexibilidade na formação, ao serem incluídas disciplinas optativas e de formação livre. Isto permite ao aluno dedicar-se mais especificamente a áreas de seu interesse, conforme a oferta de disciplinas é organizada a cada ano.

\footnotetext{
${ }^{7}$ As disciplinas assinaladas em negrito são comuns às duas habilitações.
} 


\section{Considerações finais}

Neste texto procuramos captar o momento de construção do texto curricular para um curso de Letras e destacar aspectos considerados limitadores da formação do professor em língua estrangeira. O pressuposto de que mudanças no ensino fundamental e médio passam por avanços nas concepções de como professores são formados nas licenciaturas deu suporte à análise de dois pontos básicos: a preparação para o magistério como norteadora da escolha de disciplinas e demais atividades do curso, bem como a formação de língua estrangeira como um projeto de valor em si mesmo.

Finalmente, faz-se necessário ressaltar a importância do papel da formação de professores como parte de um projeto político mais amplo para a sociedade, conforme salientam Giroux e McLaren (2002). Sem ele, podemos facilmente nos enveredar pela luta por disciplinas específicas e por carga horária, que podem até garantir nossos espaços na universidade, mas que em nada alteram o quadro educacional brasileiro, se não contribuírem para agravar as falhas hoje encontradas.

\section{Referências}

APPLE, M. Repensando ideologia e currículo. In: MOREIRA, A. F.; SILVA, T.T. (Orgs.) Currículo, cultura e sociedade. 6 ${ }^{\mathrm{a}}$. ed. São Paulo: Cortez, 2002. p. 39-58. CELANI, M. A. A. As línguas estrangeiras e a ideologia subjacente à organização dos currículos da escola pública. Claritas, v.1,_Dezembro, 1994.

CONSELHO NACIONAL DE EDUCAÇÃO - CNE. Resolução CNE/CP 1/ 2002. Diário Oficial da União, Brasília, 9 de abril de 2002. Seção 1, p. 31. Republicada por ter saído com incorreção do original no D. O. U. de 4 de março de 2002. Seção 1, p.8.

. Resolução CNE/CP2/ 2002. Diário Oficial da União, Brasília, 4 de março de 2002. Seção 1, p.9. Disponível em <http:www.mec.gov.br>.

Diretrizes Curriculares para os cursos de Letras - Parecer CES 492/2001.

Brasília. Disponível em <http:www.mec.gov.br>.

FURTOSO, V. B. Reforma curricular: da leitura das diretrizes e sua transposição ao (não) engajamento coletivo da comunidade acadêmica. Signum, Londrina, n. 6, p. 119134, 2003. 
GIMENEZ, T. ; CRISTOVAO, V;. L. L. Derrubando paredes e construindo pontes: formação de professores de língua inglesa na atualidade. Revista Brasileira de Lingüística Aplicada. Belo Horizonte, MG, v. 4, n. 2, p. 85-95, 2004.

GIMENEZ, T. Formar professores não é adendo ao bacharelado. Terra Vermelha ${ }_{2}$ junho 2003, Ano 4, n. 50, p. 10-11.

GIROUX, M.; McLAREN, P. Formação do professor como uma contra-esfera pública: a pedagogia radical como uma forma de política cultural. In: MOREIRA, A. F.; SILVA, T.T. (Orgs.) Currículo, cultura e sociedade. 6 ${ }^{\mathrm{a}}$.ed. São Paulo: Cortez, 2002. p. 125154.

LEFFA, V.J.O. O ensino de línguas estrangeiras no contexto nacional. Contexturas. APLIESP, n.4, p. 13-14, 1999.

PAIVA, V. L. M. O. A LDB e a legislação vigente sobre o ensino e a formação do professor de língua inglesa. In: STEVENS, C. M. T.; CUNHA, M. J. Caminhos e colheitas: ensino e pesquisa na área de inglês no Brasil. Brasília: UnB, 2003. p.53- 84.

PAIVA, V.L.M.O. O Novo Perfil dos Cursos de Licenciatura em Letras. In: TOMICH, et (Orgs.). A interculturalidade no ensino de inglês. Florianópolis: UFSC, 2005. p.345363.

PIMENTA, S. G. Professor reflexivo: construindo uma crítica. In: PIMENTA, S.G.;

GHEDIN, E. (Orgs.) Professor reflexivo no Brasil_- gênese e crítica e um conceito. São Paulo: Cortez, 2002. p. 17-52.

SCHÖN, D. (1983) The reflective practitioner. New York: Basic Books,1983.

SHULMAN, L. Knowledge and teaching: foundations of the new reform. Harvard Educational Review, v.57, n.1, p. 1-22, 1987.

SILVA, J. C. . 50 anos dos cursos de Letras - da Fafilon à UEL - 1956-2006. Londrina: EDUEL, 2006.

SILVA, T. T. O currículo como fetiche - a poética e a política do texto curricular. $2^{\mathrm{a}}$. Ed. Belo Horizonte: Autêntica, 2001.

TARDIF, M. Saberes docentes e formação profissional. Petrópolis: Vozes, 2002. 